\title{
AKURASI METODE IDW DAN KRIGING UNTUK INTERPOLASI SEBARAN SEDIMEN TERSUSPENSI DI MAROS, SULAWESI SELATAN
}

\author{
Gatot H. Pramono \\ Peneliti SIG di Bakosurtanal \\ Telpon: 021-875-9481 \\ E-mail: gatot@bakosurtanal.go.id
}

\begin{abstract}
Pysical conditions of seawater in coastal area can be studied by sampling at several locations. To perform spatial analysis, the data should be interpolated to get the values between sample points. Several approaches for interpolation may result in different outcomes. The purpose of this research is to compare Inverse Distance Weighted (IDW) and Kriging methods. Their parameters are studied using the total suspended sediments in Maros area, South Sulawesi. The results show that the more accurate interpolation is obtained by using IDW method than using Kriging method.
\end{abstract}

Keywords: IDW, Kriging, interpolation, suspended sediment

\section{PENDAHULUAN}

Data di wilayah pesisir perlu dipelajari untuk berbagai kebutuhan seperti perencanaan pembangunan pelabuhan, pengembangan pariwisata dan budidaya pesisir seperti ikan kerapu, rumput laut dan terumbu karang buatan. Survei lapangan perlu dilakukan untuk mengumpulkan data. Dikarenakan kondisi alam yang terkadang buruk, wilayah cakupan yang luas dan keterbatasan waktu serta dana, maka survei dilakukan dengan mengambil beberapa titik sampel pengamatan. Untuk mengolah dan menganalisa data secara spasial, Sistem Informasi Geografis (SIG) biasanya digunakan. Didalam analisa spasial baik dalam format vektor maupun raster, diperlukan data yang meliputi seluruh studi area. Oleh sebab itu, proses interpolasi perlu dilaksanakan untuk mendapatkan nilai diantara titik sampel.

Ada beberapa metode yang bisa digunakan untuk melakukan interpolasi seperti
Trend, Spline, Inverse Distance Weighted (IDW) dan Kriging. Setiap metode ini akan memberikan hasil interpolasi yang berbeda. Akan menjadi mudah dan bermanfaat bagi pengguna berikutnya apabila ada kajian tentang perbandingan hasil interpolasi dengan metode yang berbeda sehingga metode yang tepat bisa dipilih. Penggunaan metode trend dan spline telah dijelaskan dalam Pramono (2005). Penelitian ini memfokuskan pada penggunaan metode IDW dan Kriging.

Maksud dari penelitian ini adalah untuk mempelajari perbedaan akurasi hasil interpolasi dengan menggunakan metode IDW dan Kriging pada data sedimen tersuspensi di lepas pantai Kabupaten Maros, Sulawesi Selatan. Studi ini merupakan kelanjutan dari pekerjaan analisis tingkat kesesuaian marine culture yang disusun oleh Lembaga Penelitian dan Pemberdayaan Masyarakat IPB (Wiradisastra, dkk, 2004a). 
Sedang tujuan penelitian ini adalah sebagai berikut:

1. Mempelajari keuntungan dan kerugian dari interpolasi dengan menggunakan metode IDW dan Kriging,

2. Menjelaskan perbedaan hasil yang diberikan oleh kedua metode tersebut,

3. Menentukan metode yang terbaik yang dapat digunakan untuk interpolasi khususnya pada sebaran sedimen tersuspensi.

Studi ini menggunakan data yang diukur di Selat Makassar di kabupaten Maros, provinsi Sulawesi Selatan (Gambar 1). Kabupaten ini terletak pada posisi geo- grafis antara $119^{\circ} 20^{\prime} 17^{\prime}$ "BT sampai 119 31'34" BT dan 445'2” LU sampai 459' 16" LU. Batas-batas dari kabupaten Maros adalah dengan kabupaten Pangkep di bagian utara, kabupaten Bone di bagian timur, selat Makassar di bagian barat dan kota Makassar di bagian selatan. Kabupaten Maros letaknya sekitar $30 \mathrm{~km}$ utara dari ibukota Sulawesi Selatan yaitu Makassar. Oleh sebab itu, kabupaten Maros dikenal sebagai kabupaten penyangga kota Makassar.

Luas wilayah kabupaten Maros sekitar $1.613 \mathrm{~km}^{2}$ yang meliputi 14 kecamatan dan 103 desa atau kelurahan. Jumlah penduduk di kabupaten Maros pada akhir 2001 sebanyak 279.259 jiwa. Tingkat kepadatan

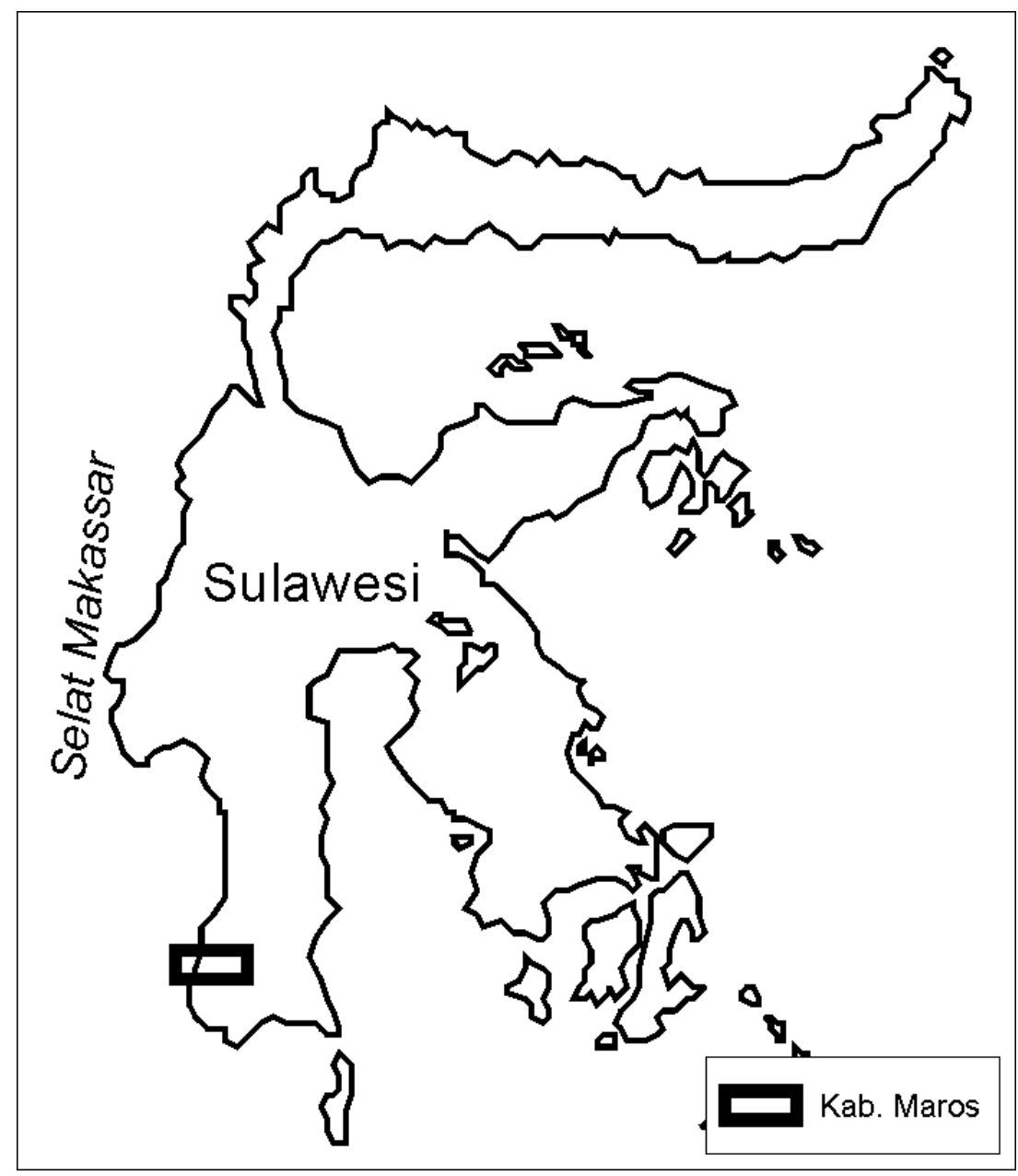

Gambar 1: Studi area di kabupaten Maros 
penduduk adalah 168 orang $/ \mathrm{km}^{2}$. Beberapa suku menghuni di kabupaten ini dengan mayoritas suku Bugis dan Makassar. Curah hujan di kabupaten Maros sangat cukup sehingga memiliki kondisi pertanian yang relatif subur. Curah hujan tertinggi didapatkan pada bulan Februari dengan nilai sekitar $839 \mathrm{~mm}$, sedang curah hujan terendah diketemukan pada sekitar bulan Juni dan Agustus.

Interpolasi adalah metode untuk mendapatkan data berdasarkan beberapa data yang telah diketahui (Wikipedia, 2008). Dalam pemetaan, interpolasi adalah proses estimasi nilai pada wilayah yang tidak disampel atau diukur, sehingga ter-buatlah peta atau sebaran nilai pada selu-ruh wilayah (Gamma Design Software, 2005). Didalam melakukan interpolasi, sudah pasti dihasilkan. Error yang dihasilkan sebelum melakukan interpolasi bisa dikarenakan kesalahan menentukan metode sampling data, kesalahan dalam pengukuran dan kesalahan dalam analisa di laboratorium.

Pada tulisan ini, akan dijelaskan penggunaan metode IDW dan Kriging untuk interpolasi. Metode IDW dapat dikelompokkan dalam estimasi deterministic dimana interpolasi dilakukan berdasarkan perhitungan matematik. Sedang metode Kriging dapat digolongkan kedalam estimasi stochastic dimana perhitungan secara statistik dilakukan untuk menghasilkan interpolasi.

\section{Metode Inverse Distance Weighted} (IDW) merupakan metode deterministik yang sederhana dengan mempertimbangkan titik disekitarnya (NCGIA, 1997). Asumsi dari metode ini adalah nilai interpolasi akan lebih mirip pada data sampel yang dekat daripada yang lebih jauh. Bobot (weight) akan berubah secara linear sesuai dengan jaraknya dengan data sampel. Bobot ini tidak akan dipengaruhi oleh letak dari data sampel.

Metode ini biasanya digunakan dalam industri pertambangan karena mudah untuk digunakan. Pemilihan nilai pada power sangat mempengaruhi hasil interpolasi. Nilai power yang tinggi akan memberikan hasil seperti menggunakan interpolasi nearest neighbor dimana nilai yang didapatkan merupakan nilai dari data point terdekat.

Kerugian dari metode IDW adalah nilai hasil interpolasi terbatas pada nilai yang ada pada data sampel. Pengaruh dari data sampel terhadap hasil interpolasi disebut sebagi isotropic. Dengan kata lain, karena metode ini menggunakan rata-rata dari data sampel sehingga nilainya tidak bisa lebih kecil dari minimum atau lebih besar dari data sampel. Jadi, puncak bukit atau lembah terdalam tidak dapat ditampilkan dari hasil interpolasi model ini (Watson \& Philip, 1985). Untuk mendapatkan hasil yang baik, sampel data yang digunakan harus rapat yang berhubungan dengan variasi lokal. Jika sampelnya agak jarang dan tidak merata, hasilnya kemungkinan besar tidak sesuai dengan yang diinginkan.

Metode Kriging adalah estimasi stochastic yang mirip dengan Inverse Distance Weighted (IDW) dimana menggunakan kombinasi linear dari weight untuk memperkirakan nilai diantara sampel data (Ctech Development Corporation, 2004). Metode ini diketemukan oleh D.L. Krige untuk memperkirakan nilai dari bahan tambang. Asumsi dari metode ini adalah jarak dan orientasi antara sampel data menunjukkan korelasi spasial yang penting dalam hasil interpolasi ESRI, 1996). Metode Kriging sangat banyak menggunakan sistem komputer dalam perhitungan. 
Kecepatan perhitungan tergantung dari banyaknya sampel data yang digunakan dan cakupan dari wilayah yang diperhitungkan.

Tidak seperti metode IDW, Kriging memberikan ukuran error dan confidence. Metode ini menggunakan semivariogram yang merepresentasikan perbedaan spasial dan nilai diantara semua pasangan sampel data. Semivariogram juga menunjukkan bobot (weight) yang digunakan dalam interpolasi. Semivariogram dihitung berdasarkan sampel semivariogram dengan jarak $h$, beda nilai $z$ dan jumlah sampel data $n$ diperlihatkan pada persamaan di Gambar 2. Pada gambar ini juga ditunjukkan grafik dari sebuah semivariogram. Pada jarak yang dekat (sumbu horisontal), semivariance bernilai kecil. Tetapi pada jarak yang lebih besar, semi-variance bernilai tinggi yang menunjukkan bahwa variasi dari nilai $₹$ tidak lagi berhubungan dengan jarak sampel point. Jenis Kriging yang bisa dilakukan adalah dengan cara spherical, circular, exponential, gaussian dan linear (ESRI, 1999). Penjelasan yang lebih lengkap tentang kelima jenis Kriging ini bisa dilihat pada McBratney \& Webster (1986).

Tahapan dalam menggunakan metode ini adalah: analisa statistik dari sampel data, pemodelan variogram, membuat hasil interpolasi dan menganalisa nilai variance. Metode ini sangat tepat digunakan bila kita mengetahui korelasi spasial jarak dan orientasi dari data. Oleh sebab itu, metode ini sering digunakan dalam bidang ketanahan dan geologi. Kelemahan dari metode ini adalah tidak dapat menampilkan puncak, lembah atau nilai yang berubah drastis dalam jarak yang dekat. Untuk keterangan lebih lanjut tentang penelitian metode Kriging bisa dilihat dalam tulisan Bancroft \& Hobbs (1986) atau Siska \& Hung (2001).

\section{METODE PENELITIAN}

Pada bagian ini akan dibahas tahapan dalam penelitian. Proses pengumpulan data atau survei lapangan dijelaskan beserta tahapan persiapan data untuk diinterpolasi. Perangkat lunak yang digunakan dan parameter yang dipelajari untuk interpolasi juga dijelaskan.

\section{Pengumpulan dan Persiapan Data}

Pengumpulan data parameter biofisik dilaksanakan oleh Lembaga Penelitian dan Pemberdayaan Masyarakat IPB

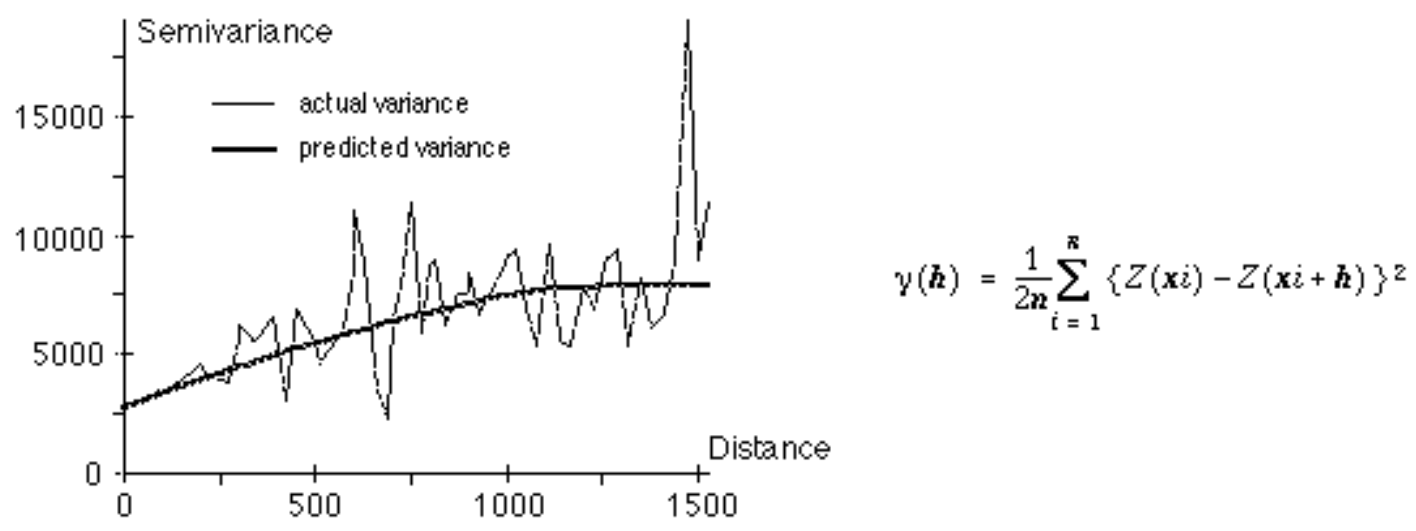

Gambar 2: Grafik dan persamaan semi-variogram (ESRI, 1999) 
(Wiradisastra, dkk, 2004b). Data yang diukur langsung adalah salinitas, oksigen terlarut, kadar keasaman $(\mathrm{pH})$, suhu permukaan dan pengambilan sampel air untuk analisis chlorofil dan sedimen tersuspensi. Total ada 45 titik yang disampel pada wilayah kabupaten Maros. Sampel air yang didapatkan kemudian dianalisa di laboratorium Limnologi, Fakultas Perikanan dan Ilmu Kelautan, Institut Pertanian Bogor.

Dari beberapa jenis data yang dikumpulkan pada survei lapangan, data sedimen tersuspensi atau Total Suspended Sediment (TSS) dipilih untuk analisa perbandingan metode interpolasi. Data tersebut dipilih karena memiliki nilai dengan standar deviasi yang cukup tinggi yaitu sekitar $17 \mathrm{mg} /$. Nilai minimum dan maksimum TSS adalah $2 \mathrm{mg} / \mathrm{l}$ dan $78 \mathrm{mg} / \mathrm{l}$. Dengan kisaran data yang cukup tinggi, diharapkan dapat memberikan hasil interpolasi yang bervariasi. Dari 45 data yang disurvei, hanya ada 23 data yang memiliki nilai TSS. Tabel 1 menunjukkan posisi survei dan nilai TSS yang didapatkan.

\section{Interpolasi Data}

Dalam penelitian ini, perangkat lunak Sistem Informasi Geografis (SIG) yang digunakan adalah ArcView versi 3.2 dari Environmental Systems Research Institute (ESRI). Untuk melakukan proses interpolasi dengan beberapa metode, digunakan ekstensi Spatial Analyst versi 1.1. Sistem operasi yang digunakan adalah Windows XP pada komputer berbasis prosesor Intel Pentium IV dengan kecepatan $2.26 \mathrm{GHz}$ dan kapasitas memori sebesar 256 Megabyte.

Salah satu kelebihan dari perangkat lunak ArcView adalah penyediaan sarana untuk kustomisasi aplikasi dengan bahasa Avenue. Interpolasi digunakan dengan menjalankan skrip Avenue dan nilainya dirubah untuk setiap model interpolasi yang dibuat. Tabel 2 menunjukkan daftar metode, parameter dan nilai yang dirubah. Untuk metode IDW, dilakukan sebanyak 8 kali simulasi dengan mengubah parameter power dan jumlah sampel. Sedang untuk metode Kriging dilakukan sebanyak 13 kali simulasi

Tabel 1. Nomer stasiun, lokasi dan nilai sedimen tersuspensi (TSS)

\begin{tabular}{|c|c|c|c|c|c|c|c|c|}
\hline Stasiun & $\begin{array}{c}\mathrm{X} \\
(\mathrm{m})\end{array}$ & $\begin{array}{c}\mathrm{Y} \\
(\mathrm{m})\end{array}$ & $\begin{array}{c}\text { TSS } \\
(\mathrm{mg} / \mathrm{l})\end{array}$ & Stasiun & $\begin{array}{c}\mathrm{X} \\
(\mathrm{m})\end{array}$ & $\begin{array}{c}\mathrm{Y} \\
(\mathrm{m})\end{array}$ & $\begin{array}{c}\text { TSS } \\
(\mathrm{mg} / \mathrm{l})\end{array}$ \\
\hline 1 & 779892 & 9455266 & 43 & & 17 & 763098 & 9462352 & 3 \\
\hline 2 & 777940 & 9455100 & 11 & & 19 & 767123 & 9459304 & 4 \\
\hline 3 & 776421 & 9454924 & 7 & & 20 & 770120 & 9459668 & 4 \\
\hline 4 & 775376 & 9454760 & 13 & & 21 & 773103 & 9459756 & 13 \\
\hline 5 & 774000 & 9454570 & 6 & & 22 & 776063 & 9459858 & 78 \\
\hline 6 & 771986 & 9454374 & 3 & & 24 & 776798 & 9452038 & 10 \\
\hline 9 & 768683 & 9460956 & 2 & & 25 & 772353 & 9451936 & 5 \\
\hline 11 & 765140 & 9465610 & 2 & & 26 & 764999 & 9450336 & 3 \\
\hline 13 & 769396 & 9473570 & 2 & & 27 & 760969 & 9449240 & 2 \\
\hline 14 & 772274 & 9473296 & 4 & & 28 & 766670 & 9453094 & 4 \\
\hline 15 & 773610 & 9466084 & 4 & & 29 & 768612 & 9454812 & 4 \\
\hline 16 & 768855 & 9464726 & 3 & & & & & \\
\hline
\end{tabular}


Tabel 2. Parameter dan nilai yang diubah dalam interpolasi
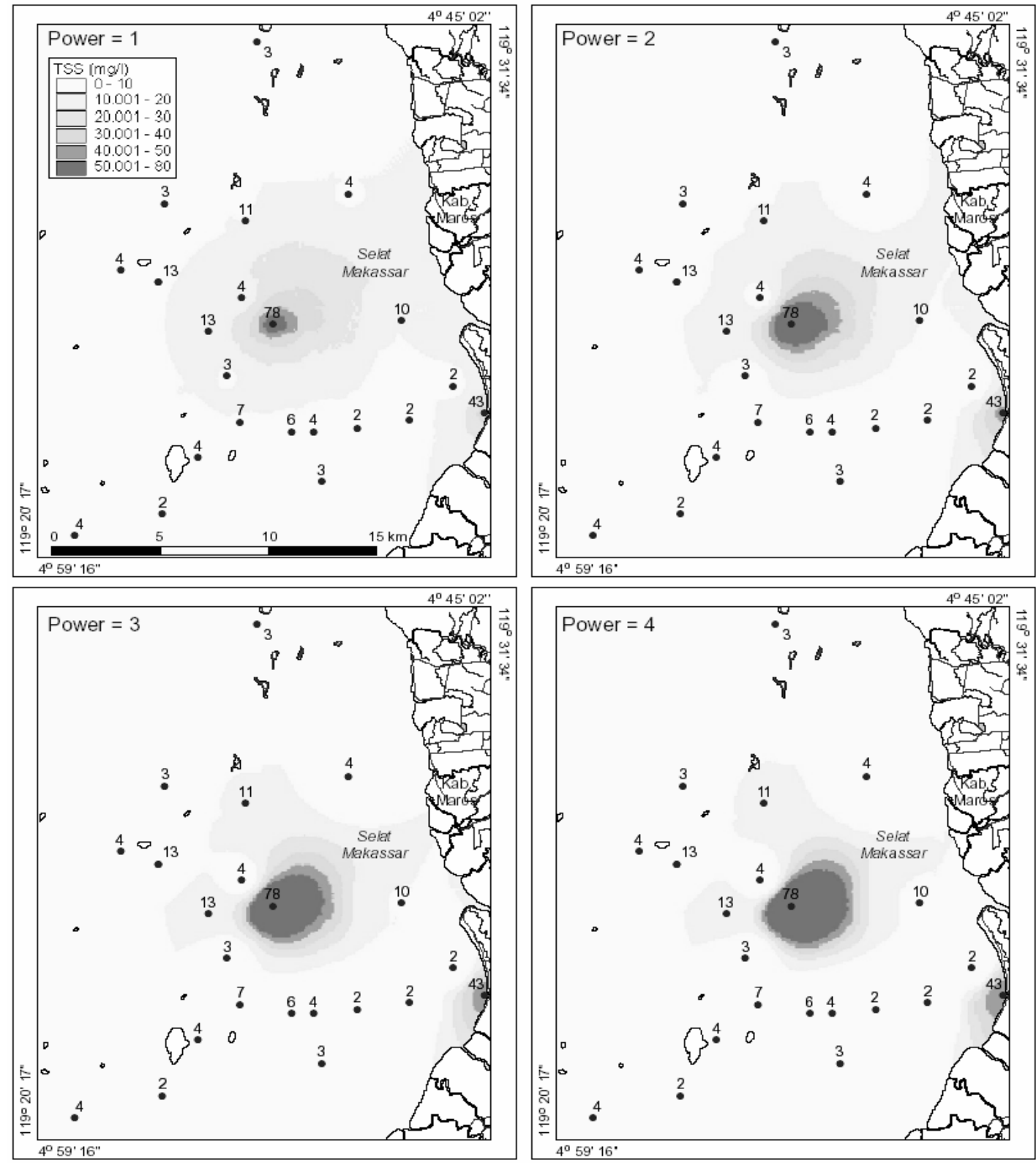

Gambar 3: Interpolasi dengan metode IDW dengan perubahan nilai power 
dengan mengubah parameter interval, tipe dan jumlah sampel. Grid data yang dihasilkan memiliki resolusi $100 \mathrm{~m}$ dan besar file hasil interpolasi sekitar 277 kilo byte.

\section{HASIL DAN PEMBAHASAN}

Pada bagian ini akan dijelaskan hasil dari proses interpolasi dengan metode IDW dan Kriging. Pada setiap metode akan dijelaskan parameter yang bisa dirubah, perhitungan statistik dan peta dari hasil interpolasi.

\section{Metode IDW}

Dalam interpolasi dengan menggunakan metode IDW, terdapat dua parameter yang bisa dipelajari yaitu power dan jumlah sampel. Hasil analisa statistik beserta peta sebarannya dibahas dalam bagian ini.

\section{Parameter Power}

Power dapat digunakan untuk menentukan pentingnya nilai sampel data pada perhitungan interpolasi. Interpolasi lokal bisa dirubah menjadi interpolasi global dengan merubah power. Power yang lebih tinggi akan menjadikan kurangnya pengaruh dari sampel data sekitarnya dan hasil interpolasi menjadi lebih detail.

Gambar 3 menunjukkan peta sebaran TSS dengan metode IDW pada nilai power yang berbeda. Terlihat bahwa semakin tinggi power, wilayah disekitar sampel dengan nilai tertinggi semakin membesar.

Hasil perhitungan statistik dari metode IDW dengan nilai power yang berbeda diperlihatkan pada Tabel 3 . Terlihat bahwa nilai minimum dan maksimum dari interpolasi mendekati atau sama dengan nilai dari sampel data. Tidak ada nilai interpolasi yang negatif atau terlalu besar. Nilai rata-rata juga menunjukkan nilai yang serupa, sedang standard deviasi naik dengan kenaikan power. Dengan demikian dapat disimpulkan bahwa merubah power tidak merubah secara drastis hasil interpolasi. Nilai hasil interpolasi juga dalam kisaran sampel data yang terkumpul dalam survei.

\section{Parameter Jumlah Sampel}

Sampel data yang digunakan adalah 2, 510 dan 15. Gambar 4 menunjukkan sebaran TSS dengan menggunakan metode IDW dengan sampel data yang berbeda. Terlihat bahwa tidak ada perubahan bentuk yang penting dengan perubahan jumlah sampel data.

Perhitungan statistik dari penggunaan metode IDW dengan jumlah sampel yang berbeda terlihat pada Tabel 4. Terlihat bahwa nilai minimum dan maksimum tidak mengalami perubahan. Sementara itu, nilai rata-rata dan standard deviasi tidak menga-

Tabel 3. Stastistik dari metode IDW dengan perubahan nilai power

\begin{tabular}{|c|c|c|c|c|}
\hline Power & Min & Max & Rata $^{2}$ & Std dev \\
\hline 1 & 2.08 & 75.91 & 8.53 & 6.39 \\
\hline 2 & 2.00 & 77.98 & 8.13 & 7.96 \\
\hline 3 & 2.00 & 78.00 & 7.89 & 9.34 \\
\hline 4 & 2.00 & 78.00 & 7.77 & 10.37 \\
\hline
\end{tabular}


Tabel 4. Stastistik dari metode IDW dengan perubahan jumlah sampel

\begin{tabular}{|c|c|c|c|c|}
\hline Sampel & Min & Max & Rata $^{2}$ & Std dev \\
\hline 2 & 2.00 & 77.99 & 7.52 & 8.54 \\
\hline 5 & 2.00 & 77.98 & 8.13 & 7.96 \\
\hline 10 & 2.00 & 77.98 & 9.41 & 6.81 \\
\hline 15 & 2.00 & 77.98 & 9.37 & 6.25 \\
\hline
\end{tabular}
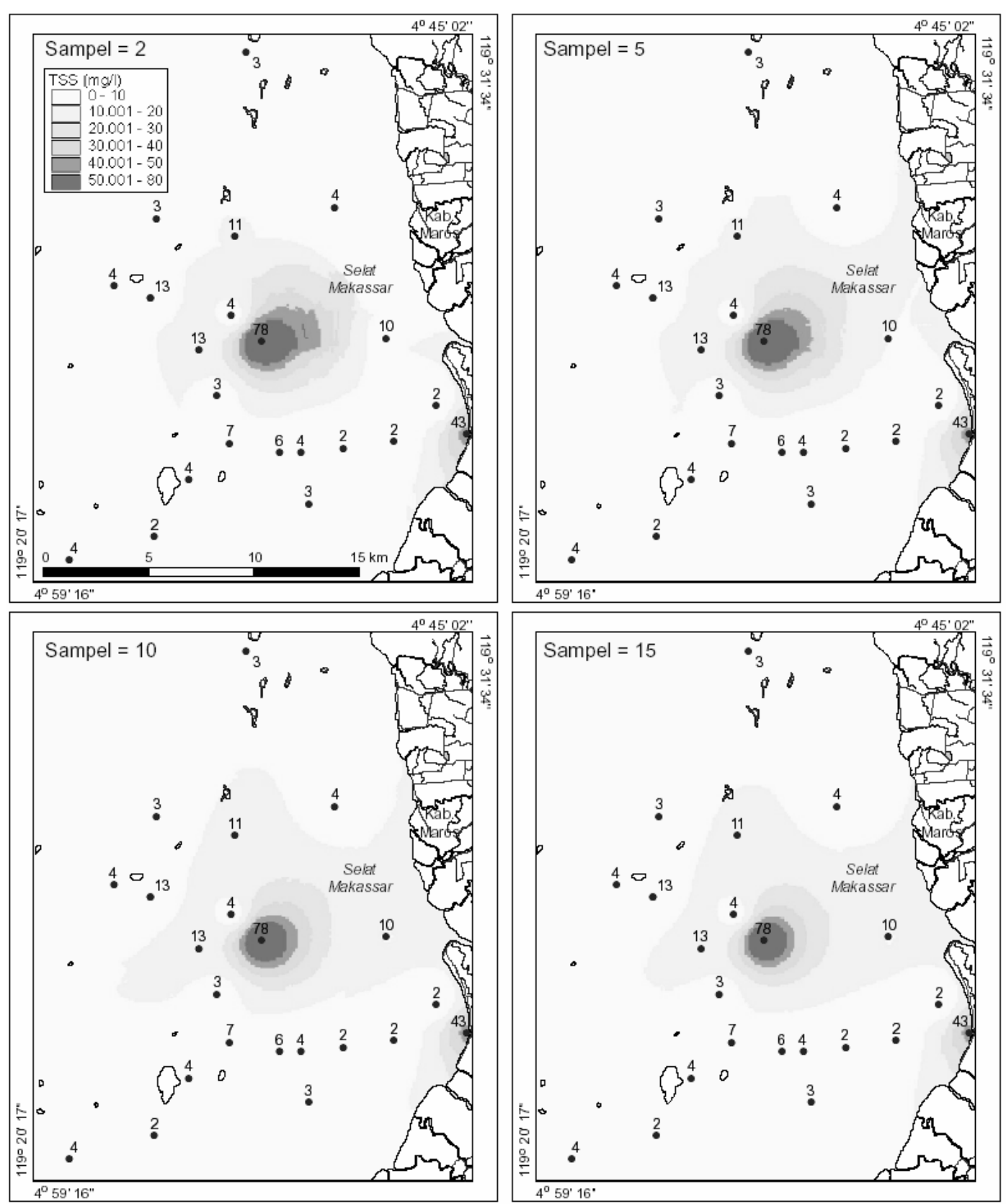

Gambar 4: Interpolasi dengan metode IDW dengan perubahan jumlah sampel 
lami perubahan yang berarti. Dengan demikian dapat disimpukan penggunaan sampel data tidak memiliki efek yang berarti dalam proses interpolasi.

\section{Metode Kriging}

Seperti yang disebutkan sebelumnya, interpolasi dengan metode Kriging memerlukan hitungan statistik dari setiap sampel data. Perhitungan statistik ini dilakukan dengan membuat semivariogram. Dalam penelitian ini, pengaruh dari parameter interval, tipe dan jumlah sampel data dipelajari.

\section{Parameter Interval}

Interval yang digunakan untuk menghitung semivariogram adalah 100 m, 200
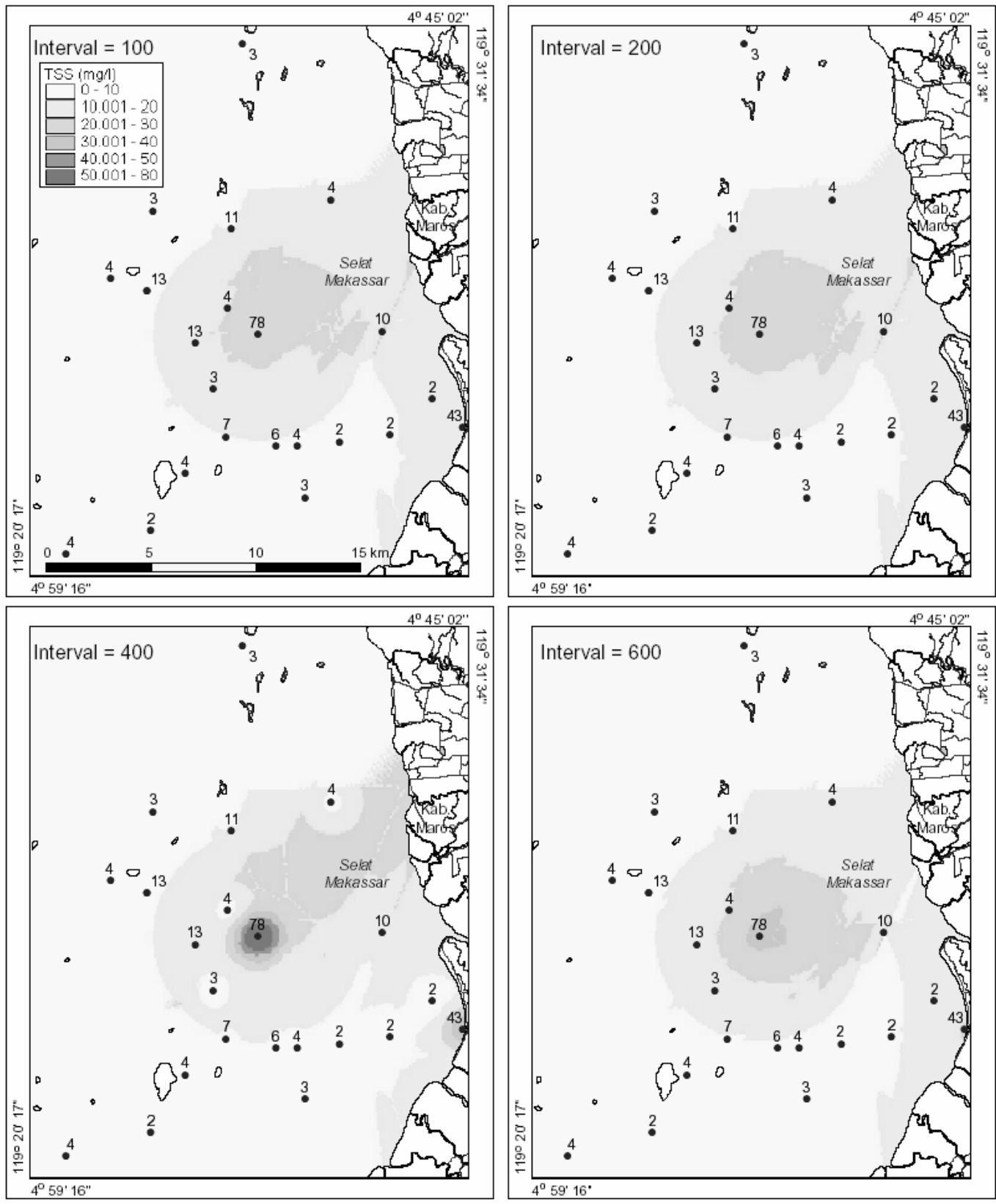

Gambar 5: Interpolasi dengan metode Kriging dengan perubahan interval 
Tabel 5. Stastistik dari metode Kriging dengan perubahan interval

\begin{tabular}{|c|c|c|c|c|}
\hline Interval & Min & Max & Rata $^{2}$ & Std dev \\
\hline 100 & 2.55 & 27.94 & 8.73 & 5.74 \\
\hline 200 & 2.54 & 30.08 & 8.81 & 5.89 \\
\hline 400 & 2.03 & 76.94 & 8.94 & 6.69 \\
\hline 600 & 2.50 & 34.99 & 8.38 & 5.93 \\
\hline
\end{tabular}

m, $400 \mathrm{~m}$ dan $600 \mathrm{~m}$. Gambar 5 menunjukkan sebaran TSS dari metode Kriging dengan interval yang berbeda. Terlihat bahwa bentuk dari sebaran TSS kurang lebih sama meskipun diproses dengan interval yang berbeda.

Tabel 5 menunjukkan stastistik dari penggunaan metode Kriging dengan jarak interval yang berbeda. Nilai minimum tidak terlalu berubah pada 100, 200 dan $600 \mathrm{~m}$ interval. Nilai maksimum yang sebanding dengan nilai maksimum dari sampel data terlihat dengan menggunakan interval sebesar $400 \mathrm{~m}$. Sedang dengan interval lain, nilai maksimum terlalu rendah dibandingkan dengan nilai maksimum data yang terkumpul. Nilai rata-rata dan standard deviasi tidak mengalami perubahan yang berarti. Dapat disimpulkan bahwa perhitungan dengan interval $400 \mathrm{~m}$ telah menunjukkan nilai minimum dan maksimum mendekati dengan nilai dari sampel data.

\section{Parameter Tipe}

Metode Kriging dapat dilakukan dengan 5 jenis pendekatan yaitu: spherical, circular, exponential, gaussian dan linear. Gambar 6 menunjukkan grid hasil interpolasi Kriging dengan tipe yang berbeda. Untuk tipe spherical bisa dilihat pada hasil Kriging dengan interval $400 \mathrm{~m}$ pada Gambar 5. Tidak terlihat perubahan pada sebaran TSS dengan penggunaan tipe yang berbeda.

Tabel 6 menunjukkan perhitungan statistik dari setiap tipe dari metode Kriging. Nilai minimum secara umum tidak begitu berubah. Sedang nilai maksimum interpolasi yang mendekati nilai maksimum sampel data terdapat pada tipe spherical dan exponential. Untuk tipe circular, gaussian dan linear, nilai maksimumnya lebih rendah yaitu kurang dari 30. Sementara itu, nilai rata-rata dan standar deviasi tidak begitu berubah dengan tipe Kriging yang berbeda. Dari sini dapat disimpulkan bahwa tipe spherical atau exponential lebih layak digunakan karena kisaran hasil interpolasi sangat mirip dengan kisaran sampel data.

\section{Parameter Jumlah Sampel}

Pada penelitian ini, jumlah sampel data yang digunakan untuk interpolasi adalah 2, 5, 10 dan 15 sampel. Gambar 7 menunjukkan sebaran TSS dari metode Kriging dengan menggunakan jumlah sampel data yang berbeda. Terlihat bahwa ketika hanya diperlukan 2 sampel data saja untuk interpolasi, bentuk mirip lingkaran terlihat mengitari pada sampel data dengan nilai maksimum. Hal ini dikarenakan sedikit sampel data yang digunakan. Sedang pada 10 dan 15 sampel terlihat beberapa lingkaran terbentuk pada sampel data kurang dari 10 . 

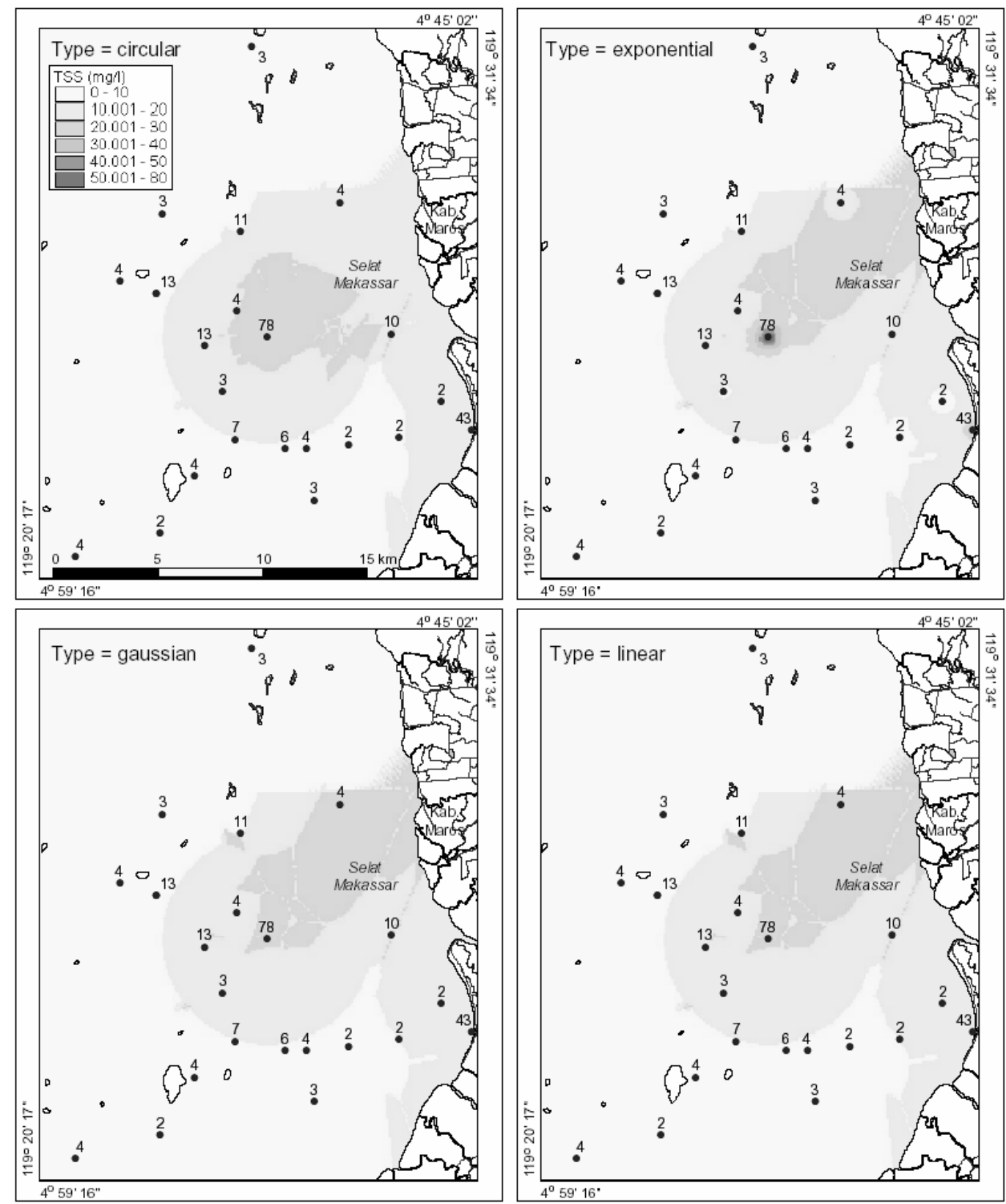

Gambar 6: Interpolasi dengan metode Kriging dengan perubahan tipe

Tabel 6. Stastistik dari metode Kriging dengan perubahan tipe

\begin{tabular}{|c|c|c|c|c|}
\hline Tipe & Min & Max & Rata $^{2}$ & Std dev \\
\hline Spherical & 2.03 & 76.94 & 8.94 & 6.69 \\
\hline Circular & 2.55 & 28.00 & 8.57 & 5.64 \\
\hline Exponential & 2.10 & 75.03 & 8.98 & 6.03 \\
\hline Gaussian & 2.60 & 27.40 & 8.99 & 5.86 \\
\hline Linear & 2.60 & 27.40 & 8.99 & 5.86 \\
\hline
\end{tabular}



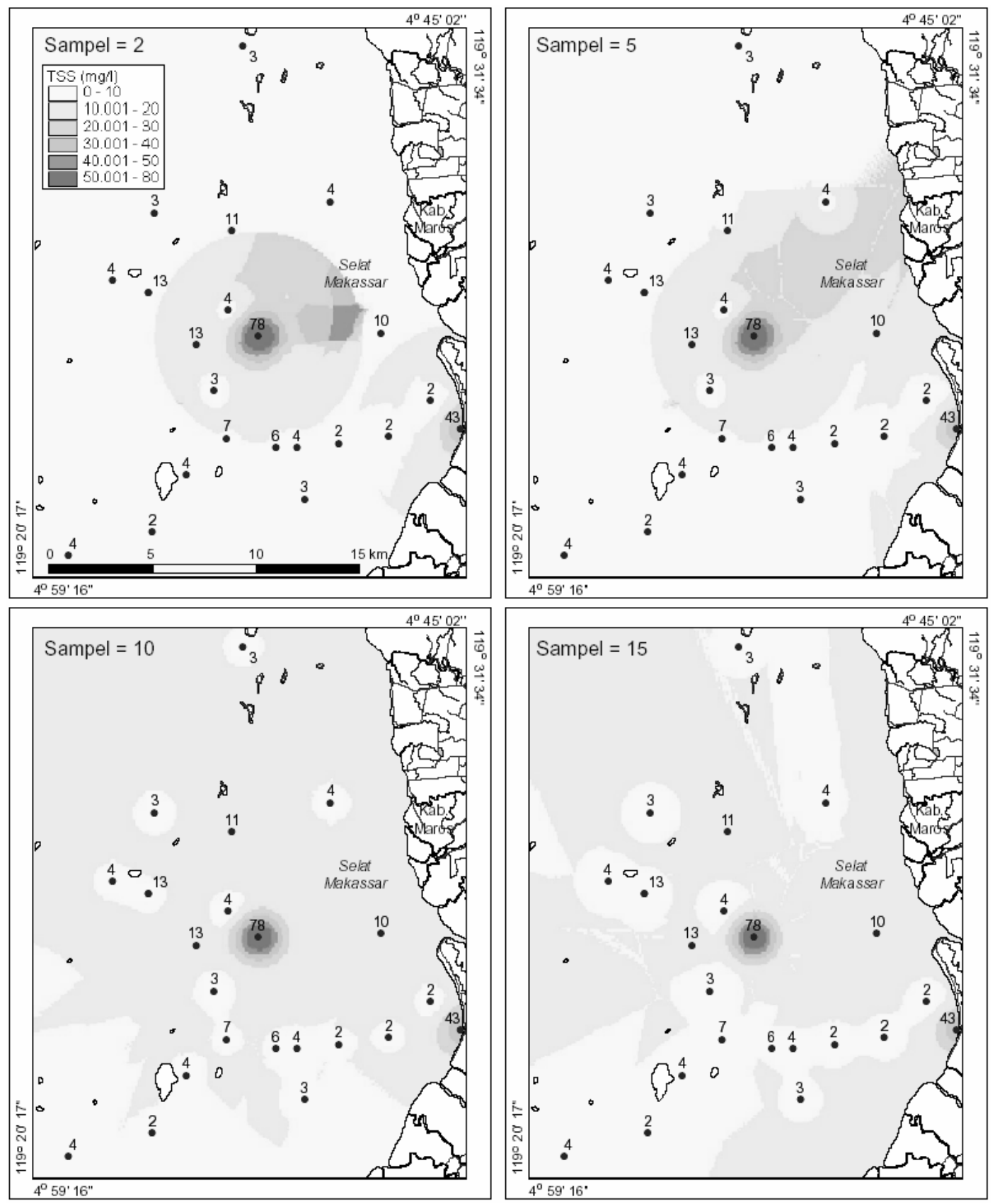

Gambar 7: Interpolasi dengan metode Kriging dengan perubahan jumlah sampel

Tabel 7. Stastistik dari metode Kriging dengan perubahan jumlah sampel

\begin{tabular}{|c|c|c|c|c|}
\hline Sampel & Min & Max & Rata $^{2}$ & Std dev \\
\hline 2 & 2.00 & 77.03 & 7.65 & 7.20 \\
\hline 5 & 2.03 & 76.94 & 8.94 & 6.69 \\
\hline 10 & 2.13 & 76.85 & 11.94 & 4.80 \\
\hline 15 & 2.30 & 76.78 & 10.99 & 3.63 \\
\hline
\end{tabular}


Perhitungan statistik dari metode Kriging dengan sampel data yang berbeda ditampilkan pada Tabel 7. Disini terlihat bahwa nilai minimum dan maksimum hasil interpolasi tidak berubah banyak dengan jumlah sampel data. Sedang nilai rata-rata yang tinggi dan standar deviasi yang rendah ditemukan pada 10-15 sampel data. Dengan ini dapat disimpulkan bahwa jumlah sampel data tidak memiliki pengaruh yang besar dalam menentukan bentuk sebaran data dan beberapa parameter statistik.

\section{KESIMPULAN DAN REKOMENDASI}

Beberapa hal dapat disimpulkan dari penelitian perbandingan metode interpolasi Inverse Distance Weighted (IDW) dan Kriging dengan menggunakan data total suspended sediment (TSS) yaitu sebagai berikut:

1. Metode IDW memberikan hasil interpolasi yang lebih akurat dari metode Kriging. Hal ini dikarenakan semua hasil dengan metode IDW memberikan nilai mendekati nilai minimum dan maksimum dari sampel data. Sedang metode Kriging terkadang memberikan hasil interpolasi dengan kisaran yang rendah. Opsi power dan jumlah sampel tidak memberikan perubahan yang signifikan pada hasil interpolasi.

2. Jika ingin menggunakan metode Kriging, opsi interval $400 \mathrm{~m}$ dan tipe spherical atau exponential perlu dipilih untuk proses interpolasi karena menghasilkan data yang mendekati kisaran dari sampel data. Hal ini tentu disesuaikan dengan skala dan resolusi grid yang dibuat.

Sedang rekomendasi yang bisa disampaikan adalah sebagai berikut:

1. Untuk penelitian kedepan, metode interpolasi sebaiknya diujikan juga dengan data yang telah disurvei pada lokasi yang sama seperti suhu permukaan, $\mathrm{pH}$, chlorophyl dan lain-lain. Hal ini akan memastikan apakah metode yang sama bisa digunakan untuk data dengan kisaran dan nilai yang berbeda.

2. Penelitian yang juga masih terbuka adalah perbandingan metode interpolasi pada sebaran data TSS yang berbeda. Ada kemungkinan bahwa metode interpolasi yang lain bisa lebih unggul dengan input sampel data yang lengkap pada jarak yang teratur.

3. Didalam hal survei lapangan, akan lebih baik untuk mengumpulkan sampel yang mencakup wilayah studi secara tersebar dan merata. Hal ini akan berpengaruh pada kualitas interpolasi. Selain itu sampel yang tersebar secara merata juga memungkinkan digunakan untuk mengecek keberhasilan hasil interpolasi secara lebih baik.

\section{DAFTAR PUSTAKA}

Bancroft, B.A. \& Hobbs, G.R. 1986. Distribution of Kriging Error and Stationarity of the Variogram in a Coal Property. Mathematical Geology 8(7): 635-651.

ESRI. 1996. Using the ArcView Spatial Analyst. Redlands, Environmental Systems Research Institute, Inc. 
ESRI. 1999. ArcView Help. Redlands, Environmental Systems Research Institute, Inc.

Haryanto. 2004. "Bahaya Perubahan Penggunaan Lahan di Kota Semarang". Forum Geografi, Vol. 18, No. 2, Desember 2006. Hlm. 152-160.

Gamma Design Software. 2005. Interpolation in GS+. http://www.geostatistics.com/ OverviewInterpolation.html (23 Juni 2008).

McBratney, A.B. \& Webster, R. 1986. Choosing Functions for Semivariograms of Soil Properties and Fitting Them to Sampling Estimates. Journal of Soil Science 37:617639.

NCGIA. 2007. Interpolation: Inverse Distance Weighting. http://www.ncgia.ucsb.edu/pubs/ spherekit/inverse.html (23 Juni 2008).

Pramono, G. 2005. Perbandingan Metode Trend dan Spline untuk Interpolasi Sebaran Sedimen Tersuspensi Di Kabubaten Maros, Sulawesi Selatan. Jurnal Ilmiah Geomatika 11(1): 20-32.

Siska, P.P. \& Hung, I.K. 2001. Assesment of Kriging Accuracy in the GIS Environment. http:// gis.esri.com/library/userconf/proc01/professional/ papers/pap280/p280.htm (23 Juni 2008).

Suprapto Dibyosaputro. 2005. "Muatan Suspensi Total dan Laju Sedimentasi Sungai Kayan di Kabupaten Bulungan, Kalimantan Timur". Forum Geografi, Vol. 19, No. 2, Desember 2005. Hlm. 115-126.

Watson, D.F. \& Philip G.M. 1985. A Refinement of Inverse Distance Weighted Interpolation. GeoProcessing 2: 315-327.

Wikipedia. 2008. Interpolasi. http://en.wikipedia.org/wiki/Interpolation (23 Juni 2008)

Wiradisastra, U.S. dkk. (2004a). Laporan Akhir - Analisis Tingkat Kesesuaian Marine Culture Wilayah ALKI II, Buku II (Kajian ilmiah). Bogor, Lembaga Penelitian dan Pemberdayaan Masyarakat, IPB.

Wiradisastra, U.S. dkk. (2004b). Laporan Akbir - Analisis Tingkat Kesesuaian Marine Culture Wilayah ALKI II, Buku I (Teknis - analisis). Bogor, Lembaga Penelitian dan Pemberdayaan Masyarakat, IPB. 